\title{
Relatório da excursào científica realisada na zona da Estrada de Ferro Noroeste do Brasil em Julho de 1939 *
}

\author{
por \\ Lauro Travassos e J. F. Teixeira de Freitas \\ (Com 5 figuras no texto)
}

No relatório da excursão feita em outubro do ano passado salientamos as vantagens destes estudos e fizemos uma descrição sumária das zonas percorridas pela Estrada de Ferro Noroeste do Brasil.

Esta segunda excursão foi realizada por iniciativa do Clube Zoológico do Brasil. Resolvida a viagem recorremos à clarividência do Major Marinho Lutz, que prontamente nos concedeu um carro dormitório e um breque ou carro de bagagem da Estrada que com tanta eficiência vem dirigindo.

O Exército Nacional muito facilitou nossa expedição, tendo o Sr. General Gaspar Dutra ordenado à 9. ${ }^{\circ}$ Região Militar prestasse todo o auxilio que carecessemos e fizesse agregar à nossa comitiva um oficial da região.

A Estrada de Ferro Sorocabana nos concedeu condução de São Paulo à Baurú.

Tivemos, pois, mais uma vez, imensas facilidades e valiosos auxílios prontamente obtidos.

A comitiva era constituida por socios do Clube Zoológico do Brasil, por funcionários do Departamento de Zoologia da Secretaria de Agricultura do Estado de S. Paulo, um técnico do Instituto de Higiene deste mesmo Estado e quatro outros do Instituto Osvaldo Cruz. À ela se reuniu, em Aquidauana, um tenente veterinário.

Aos primeiros competia o aprovisionamento da comitiva e captura de exemplares para estudos. Aos técnicos do Departamento de Zoologia da Secretaria de Agricultura coube, principalmente, a preparação dos vertebra-

* Recebido para publicação a 25 de junho dè 1939 e dado à publicidade em abril de 1941. 
dos capturados e seu estudo posterior; ao representante do Instituto de Higiene o estudo dos culicideos; aos do Instituto Osvaldo Cruz as pesquisas parasitológicas e observações medicas e ao tenente veterinário que nos acom. panhou à missão de atender aos casos de sua especialidade, assim como providenciar a obtenção de animais para isca de insetos e outros requisitos que se tornassem necessários na região, da qual era um bom conhecedor.

A região escolhida foi a vila de Salobra, à margem esquerda do rio Miranda, onde haviamos acampado na viagem anteric, e ainda os aricidores da cidade de Campo Grande, em regiões de campo, de grande interêsse para a captura de algumas espécies.

A bôa vontade e o espírito de camaradagem e colaboraçao de todos os componentes da expedição muito concorreram para o êxito que dela resultou. sendo muito produtiva em material e observações científicas, ampliando nossos conhecimentos sôbre uma região de grande importância futura.

\section{Componentes da expedição}

A expedição foi dividida nas quatro seguintes equipes :

1 - Equipe do Clube Zoológico do Brasil, constituida pelos Srs. Nicolau Tebecherani (responsavel), Salim Lutfalla, Nagib Scaff e Jorge Gebara, industriais paulistas e caçadores experimentados. A esta equipe se incorporou em Lins o Sr. Orlando Tremocoldi. Ao esforço e capacidade de obtençãc de exemplares para estudos dos sócios do Clube Zoológico devemos grande parte do êxito obtido em nossas pesquisas.

2 - Equipe do Departamento de Zoologia da Secretaria de Agricultura. constituida pelos Srs. Frederico Lane (responsavel), entomologista e nosso companheiro da viagem anterior, Carlos C. Vieira, ornitologista, João Leonardo de Lima e Mário Leonardo de Lima, taxidermistas e Affonso M. Olalla, conhecido colecionador e explorador da região amazonica.

3 - Equipe do Instituto de Higiene, representada sómente pelo $\mathrm{Sr}$. John Lane, entomologista, encarregado do levantamento culicidico da região.

4 - Equipe do Instituto Osvaldo Cruz, composta por Lauro Travassos (responsavel pela expedição), J. F. Teixeira de Freitas, encarregados das pesquisas parasitológicas e observações médicas, Mário da Silva Ventel e Antônio da Rocha Nobre, auxiliares técnicos. A esta equipe se incorporou, em Aquidauana, o tenente veterinário Jairo $\Gamma$ o. tes, cujo espírito disciplinado e colaboracior nos foi de grande valia. 


\section{A viagem}

Partimos do Rio às 20 horas do dia 16 de Julho, chegando pela manhã do dia seguinte à São Paulo, onde logo nos puzemos em contato com os demais membros da expedição. Durante o decorrer do dia aceríamos os últimos detalhes com o Diretor do Departamento de Zoologia da Secretaria de Agricultura do Estado e com o Presidente do Clube Zoológico do Brasil, tomando as últimas providências necessárias.

Pariinos de São Pá ío às 20,45 horas, já instalados nos carros da Estrada de Ferro Noroeste do Brasil, chegando a Baurú pela marhã do dia 18. Nesta cidade nos avistamos com os engenheiros da Estrada Noroeste Drs. Amarante e sntenor Borges, que nos dispensaram todas as atenções, dando as ordens necessárias para que a viagem corresse sem contratempos. Partimos de Baurú às 20,20 horas, chegando a Araçatuba no dia 19 às 7,20 horas.

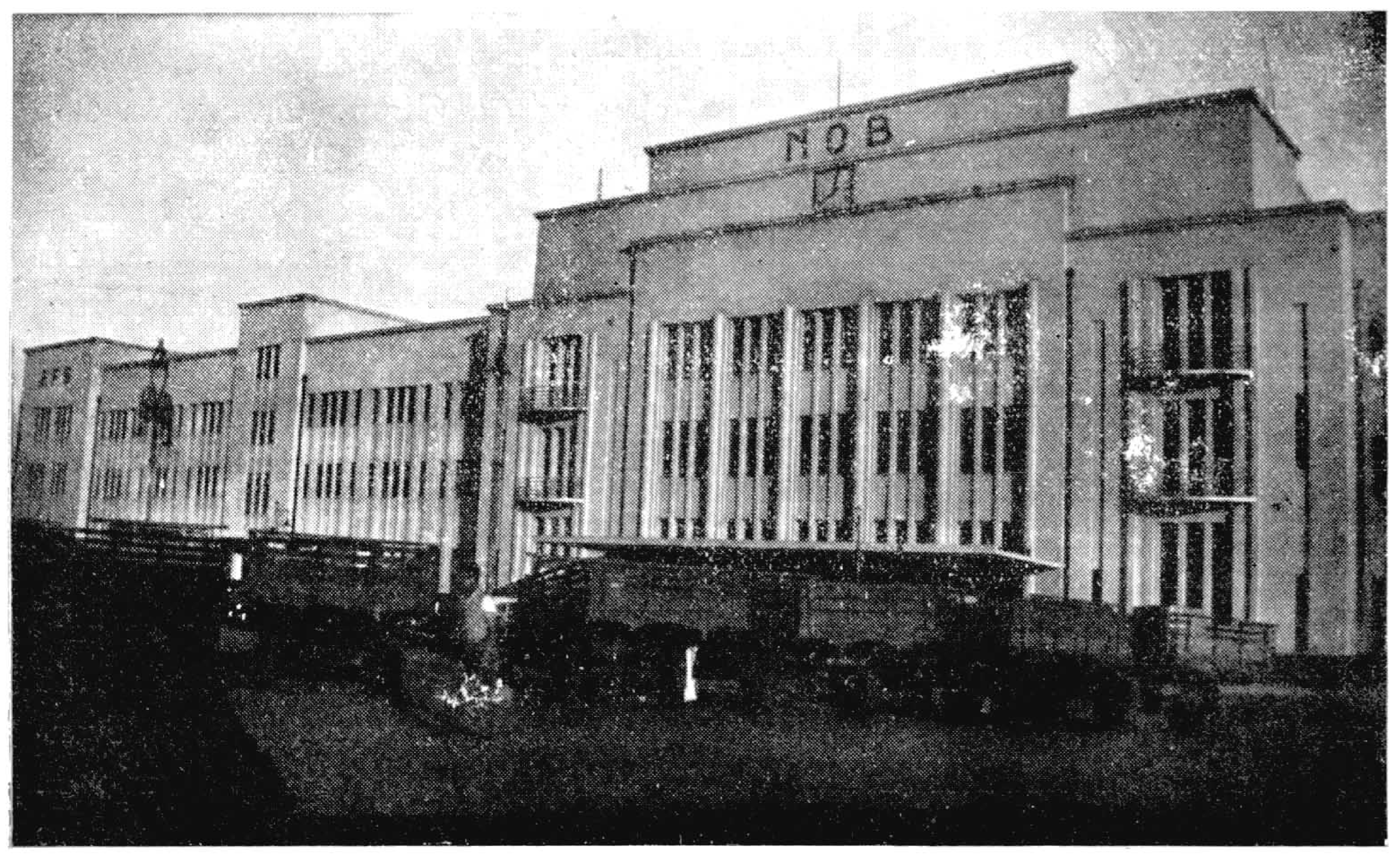

Fig. 1 - Estação da Estrada de Ferro Noroeste do Brasil, em Baurú.

De Araçatulì até o rio Paraná o percurso foi feito pela nova variante, ainda desconhecida para nós e inaugurada a cerca de dois anus.. Apresenta esta zona impressionante progresso, correndo a linha ferrea, em vários trechos, em plena floresta vir,,${ }^{\prime}$, o que constitue um encanto para o nat'iralista. Agradavel impressão tivemos neste trecho, ao depararmos com as con- 
fortaveis instalações do pessoal da Estrada, sempre constituidas por apraziveis habitações.

Chegamos a Três Lagoas cerca de 15 horas e ai permanecemos $50 \mathrm{mi}$ nutos que aproveitamos para colher informações sobre uma "coceira" que afeta aos banhistas da lagoa próxima. Esta lagoa, que dista algumas dezenas de metros da cidade, tem as orlas guarnecidas de juncos numa largura de 4 a 6 metros. E' nesta faixa que reside a causa da "coceira", motivo pelo qual a Prefeitura local fez construir uma ponte de madeira, de modo a evitar o contato dos banhistas com a vegetação. Três Lagoas é edificada em terreno arenoso e de aparência bastante saudavel. Sua visinhança com Jupiá, situada na barranca do rio Paraná e distante apenas 9 quilômetros, e grande fóco de impaludismo, permite frequentes surtos dessa endemia. E' de grande interêsse uma excursão nesta localidade. visando o estudo das causas da "coceira" produzida pela lagoa de sua visinhança e as possibilidades da existência aí de impaludismo endemico, visto ser um ponto de aquartelamento de uma parte da guarnição da 9. ${ }^{a}$ Região Militar.

Partimos de Três Lagoas à tarde, chegando a Campo Grande às 6,50 horas do dia 20, sendo recebidos na gare pelo Coronel Estillac Leal que nos

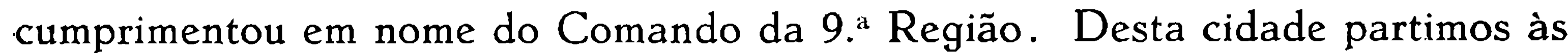
7,50 , parando em Aquidauana, onde se incorporou à comissão o tenente Jairo Pontes, nosso antigo discípulo. Finalmente chegamos à Salobra às 16 horas .

Nesta mesma tarde instalamos os laboratórios e cosinha em uma pequena casa da Estrada, situada em frente à Estação. Foram tiradas ainda as primeiras informações sôbre as condições de salubridade da região, que, aliás. eram bastante más, devido ao impaludismo que então grassava de modo extremamente violento.

No dia 21, ao romper do dia, tiveram início os trabalhos, que se prolongaram sempre até horas avançadas da noite. No dia 24 uma parte da comitiva foi destacada para operar nos arredores de Campo Grande, devendo se reincorporar em nosso regresso. Em Campo Grande o Comando da Região forneceu um caminhão para conduzir os expedicionários aos pontos mais propícios à obtenção de exemplares de campo, de grande interêsse para o Departamento de Zoologia da Secretaria de Agricultura. Infelizmente o exame parasitológico dêstes exemplares não poude ser feito, porquanto o técnico destacado para estas pesquisas. Sr. Mário Ventel, teve a urgente necessidade de regressar ao Rio, por morte de um parente. No dia 26 os expedicionários estacionados em Salobra ficaram desfalcados de outro companheiro, Sr. Afonso Olalla, que regressou, doente, a São Paulo. 


\section{Condições da época da excursão}

A excursão foi realizada em plena estação fria e no fim da vasante de pequena enchente do rio Miranda, época ainda pouco propícia à obtenção de abundante material científico para estudo, porem extremamente valiosa para a população da localidade, totalmente vitima da malária. E' de notar que há vários anos não se observam grandes enchentes na região, cujo ciclo, segundo moradores locais, é de 7 anos.

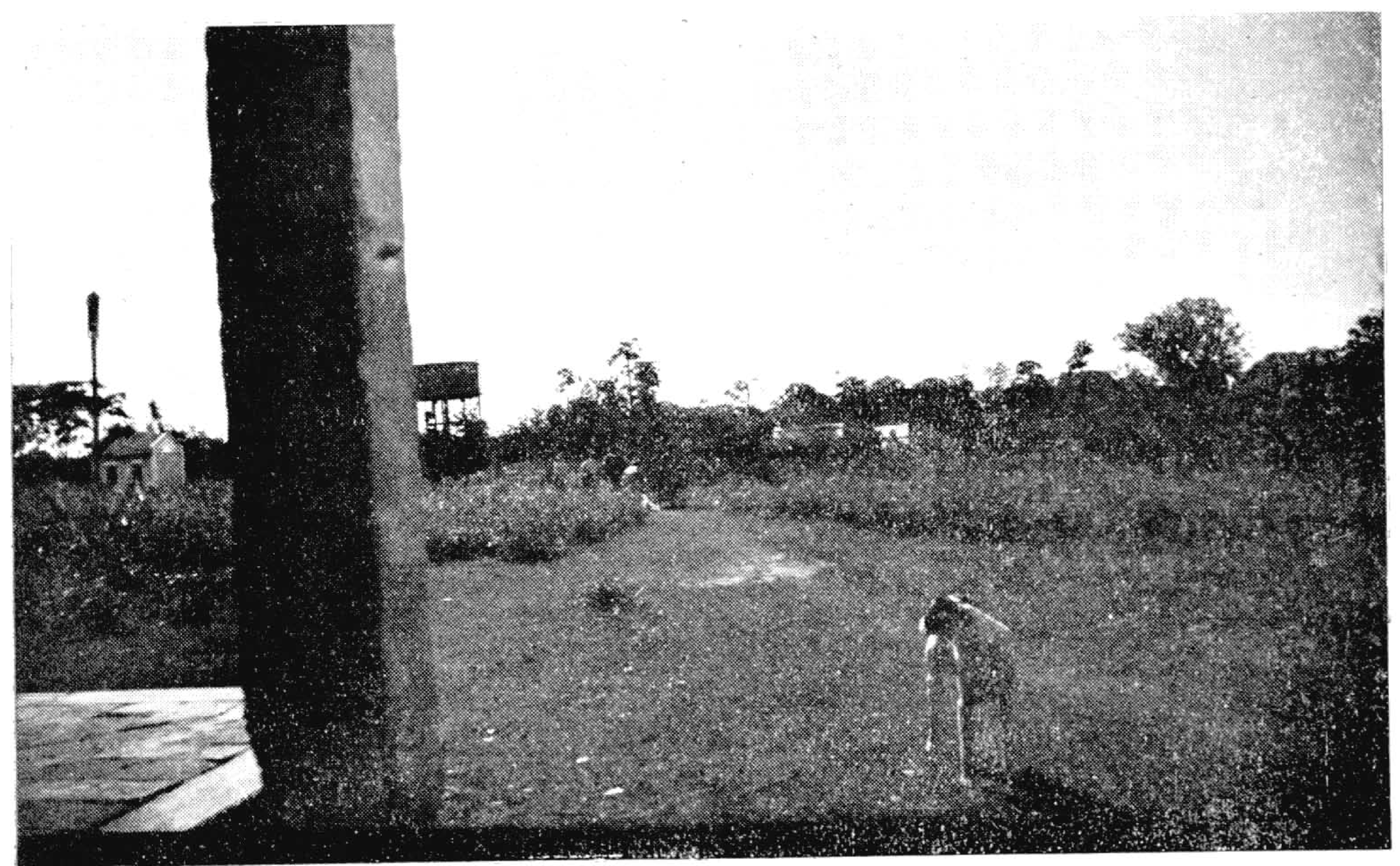

Fig. 2 - Aspecto de Salobra.

Em Salobra nos aguardava grande surpresa - localidade onde, no ano anterior, em época quente (fim de Outubro) com dificuldade haviamos capturado alguns mosquitos, fomos agora recebidos por um aluvião destes insetos, entre os quais predominavam os anofelineos com cerca de $95 \%$. Como consequência. a quasi totalidade dos habitantes estava impaludada. em oposição ao observado anteriormente, quando não existia um só caso de malária no local. A sadia vila de Salobra de Outubro de 1938 se transformara em Julho de 1939 em um acampamento de paludicos. Submetemo-nos a rigorosa quininisação preventiva e com os medicamentos distribuidos conseguimos suprimir os casos febrís, não mais existentes quando nos retiramos no dia 31. 
Os trabalhos foram bastante frutiferos, sob o ponto de vista parasitológico, nos sendo possivel examinar 432 animais. O desempenho da parte medica da comissão foi coroado de completo êxito na pequena localidade em que estivemos 10 dias. A obtenção de material zoológico desta interessante região foi bastante proveitosa em vários grupos, destacando-se logo, a coleção de aves, recolhida ao Departamento de Zoologia da Secretaria de Agricultura do Estado de S. Paulo, e estudada por Carlos C. Vieira, e, tambem, a enorme quantidade de mosquitos coletada por J. Lane e recolhida ao Instituto de Higiene de São Paulo, onde será estudada por este pesquisador.

A equipe destacada para Campo Grande foi menos feliz por ter sido surpreendida por uma onda de frio e chuvas torrenciais. Não obstante, capturaram vários exemplares da nossa fauna ornitológica, recolhidos tambem ao Departamento de Zoologia.

Resumo do material coletado

Pesquisas parasitológicas

Animais examinados.

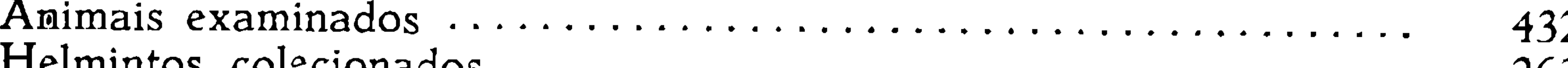

263 amostras

Esfregaços de orgãos ou de sangue $\ldots \ldots \ldots \ldots \ldots \ldots \ldots \ldots .414$

Material entomológico

Insetos capturados $\ldots \ldots \ldots \ldots \ldots \ldots \ldots \ldots \ldots \ldots \ldots \ldots \ldots, 4.240$

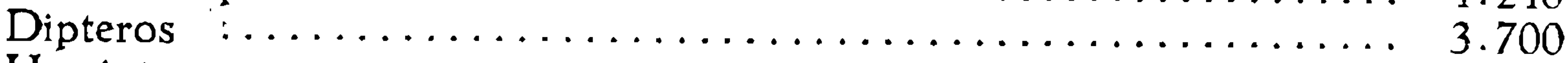

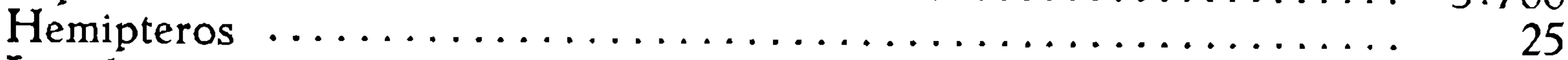

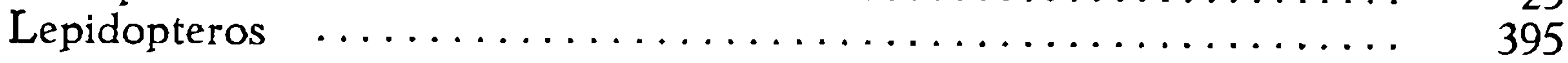

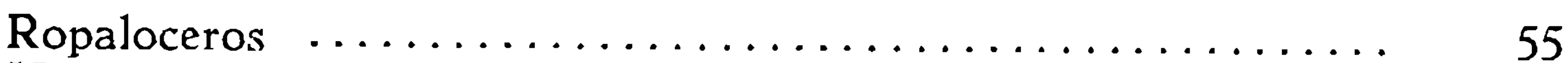

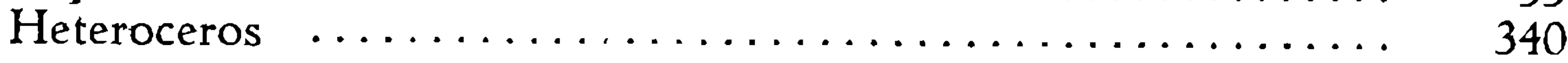

Sphingidae .......................... 16

Adelocaphalidae (sin.: Syssphingidae) ............. 3

Euchromiidae ............................. 104

Arctiidae ............................. 50

Hemileucidae $\ldots \ldots \ldots \ldots \ldots \ldots \ldots \ldots \ldots \ldots \ldots \ldots \ldots \ldots \ldots$

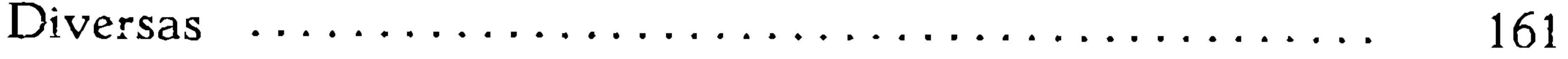

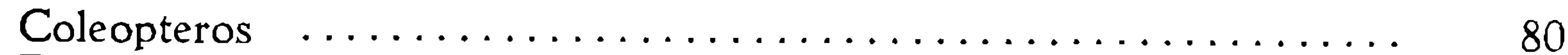

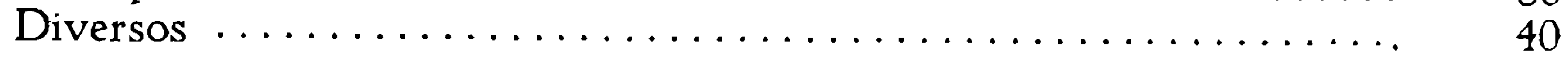

Vários moluscos, araneideos e pseudo escorpionideos foram tambem colecionados.

Vertebrados colecionados

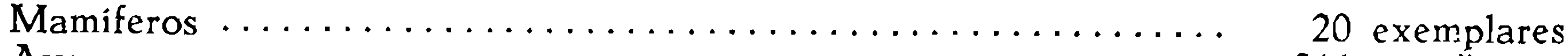

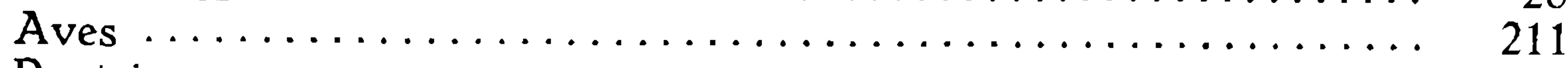

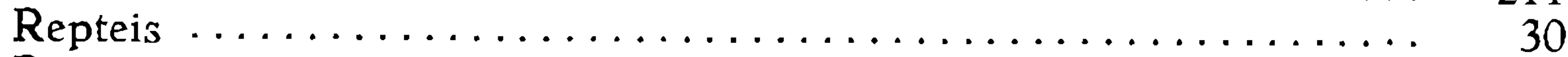

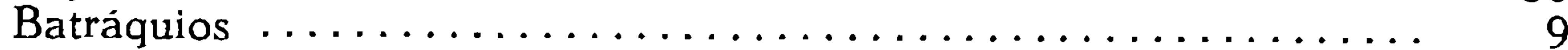

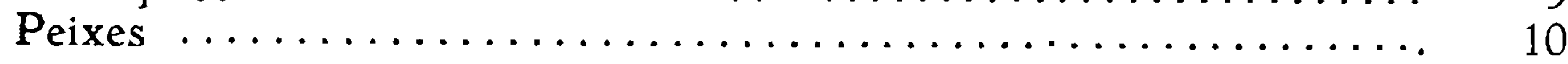

Foram trazidos os figados das 19 piranhas autopsiadas, conservados em sal, para pesquisa de vitaminas. 


\section{PESQUISAS PARASITOLÓGICAS}

As pesquisas parasitológicas foram feitas, em sua totalidade, em Salobra. Foram examinados 432 animais, durante os 10 dias de permanência naquele ponto, com a média diária de 43,2 autópsias. As 414 lâminas com esfregaços foram examinadas por D. Gisela Runge, tendo dado como resultado a positividade para microfilárias em 19 lâminas e para hemoprotozoários em 10 lâminas. Todos os animais examinados eram vertebrados, assim distribuidos :

\begin{tabular}{|c|c|c|c|c|c|c|c|c|}
\hline Mamiferos & -18 & exemplares & 8 & espécies) & - & $4,1 \%$ & do & total \\
\hline Aves & -351 & $"$ & $(108$ & $"$ & - & $81,2 \%$ & , & 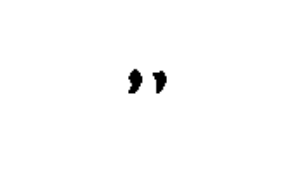 \\
\hline Repteis & -28 & " & ( 4 & $"$ & - & $6,4 \%$ & $"$ & \\
\hline Batráquios & - & $"$ & 2 & $"$ & - & $1,6 \%$ & $"$ & \\
\hline Peixes & -28 & " & ( 7 & ) & - & $6,4 \%$ & $"$ & \\
\hline
\end{tabular}

Os helmintos colecionados atingem a 263 amostras, assim distribuidas :

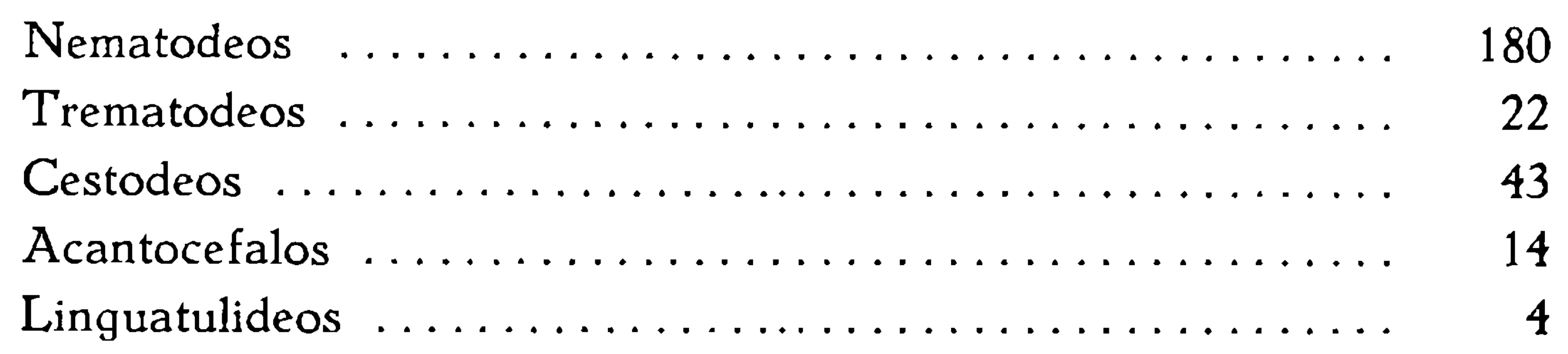

Dos 432 animais examinados 173 se apresentavam parasitados por helmintos, isto é, cerca de $40 \%$. O parasitismo geral, por grupo de helmintos, é o seguinte :

\begin{tabular}{|c|c|c|c|c|c|c|}
\hline Parasitados & por & nematodeos & - & 140 & exemplares & $-80,9 \%$ \\
\hline " & $"$ & trematodeos & - & 20 & & $-11,3 \%$ \\
\hline " & & cestodeos & - & 42 & " & $-24,2 \%$ \\
\hline " & $"$ & acantocefalos & - & 14 & $"$ & $-8,0$ \\
\hline ," & & linguatulideos & - & 4 & . & $-\quad 2,3$ \\
\hline
\end{tabular}

O parasitismo por helmintos nos grupos de vertebrados é :

\begin{tabular}{|c|c|c|c|}
\hline Mamiferos & \multicolumn{3}{|c|}{11 exemplares - 61,1\% } \\
\hline Aves $\ldots$ & 125 & $"$ & \\
\hline Repteis & 17 & $"$ & $-60,7 \%$ \\
\hline Batráquios & 2 & $"$ & $-28,5 \%$ \\
\hline Peixes & 18 & $"$ & $-64,2$ \\
\hline
\end{tabular}


O parasitismo por grupo de helmintos nos grupos de vertebrados é :

\section{Mamíferos}

\begin{tabular}{|c|c|c|c|c|c|c|}
\hline arasitados & por & nematodeos & - & 11 & exemplares & $-100 \%$ \\
\hline " & 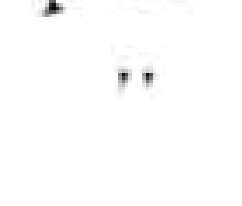 & trematodeos & - & 0 & " & - \\
\hline$"$ & , & cestodeos & - & 2 & " & $-18,1 \%$ \\
\hline , & " & acantocefalos & - & 1 & . & $9 \%$ \\
\hline " & " & linguatulideos & - & 0 & & \\
\hline
\end{tabular}

Aves

\begin{tabular}{|c|c|c|c|c|c|c|}
\hline Parasitados & por & nematodeos & - & 98 & exemplares & $-78,4 \%$ \\
\hline$"$ & " & trematodeos & - & 17 & $"$ & $-13.6 \%$ \\
\hline " & " & cestodeos & - & 36 & " & $-28,8 \%$ \\
\hline$"$ & " & acantocefaios & - & 13 & $"$ & $-10,4$ \\
\hline$"$ & $"$ & linguatulideos & - & 0 & & \\
\hline
\end{tabular}

\section{Repteis}

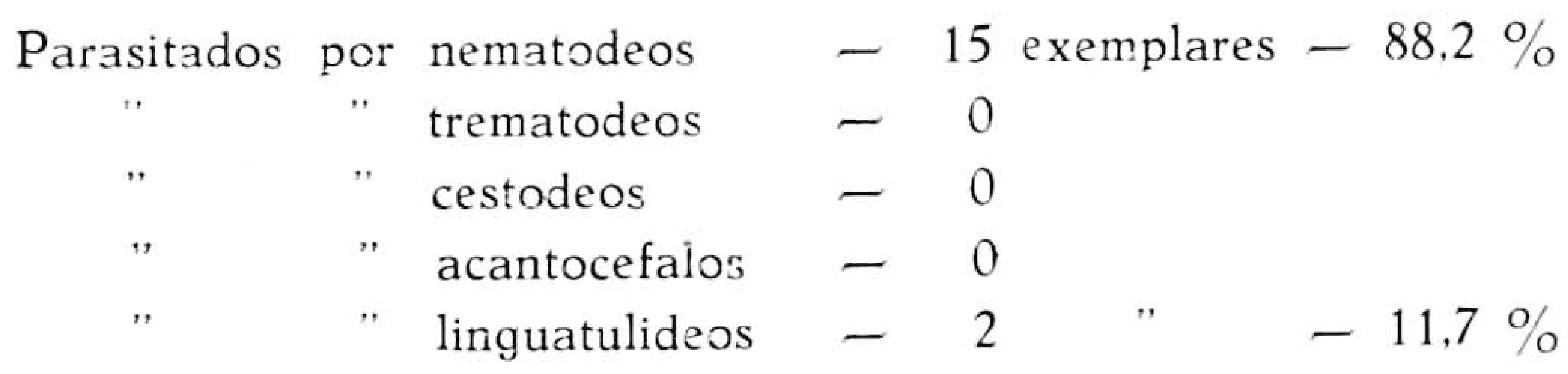

\section{Batraquios}

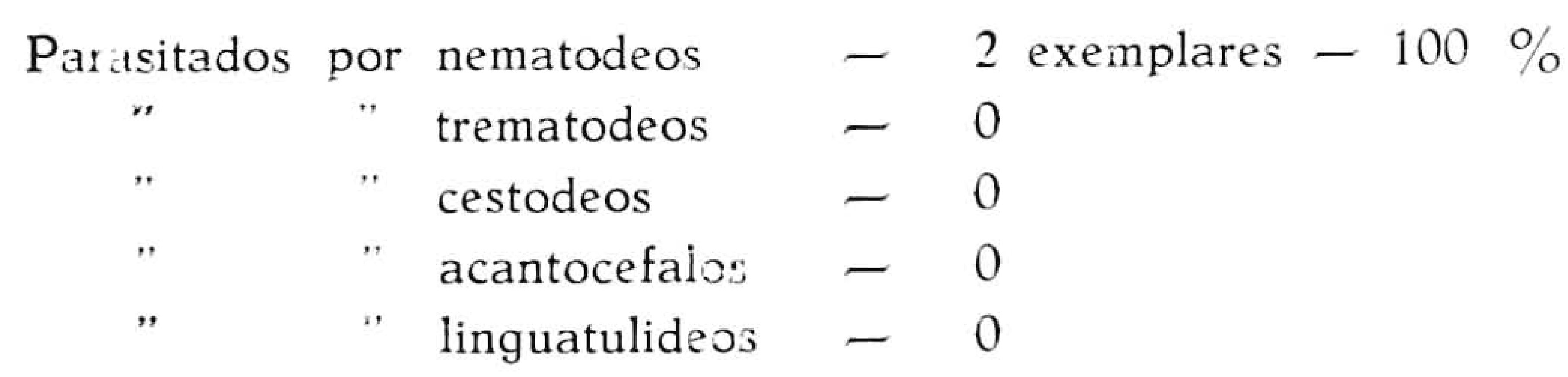

\section{Peixes}

\begin{tabular}{|c|c|c|c|c|c|c|}
\hline Parasitados & por & nematodeos & - & 14 & exemplares & $-77.7 \%$ \\
\hline$"$ & $\because$ & trematodeos & - & 3 & " & $-16,1 \%$ \\
\hline$"$ & $"$ & cestodeos & - & 4 & $"$ & $-22,2$ \\
\hline " & " & acantocefalos & - & 0 & & \\
\hline " & $"$ & linguatulideos & - & 2 & $"$ & 1,1 \\
\hline
\end{tabular}


LISTA SISTEMÁTICA DOS ANIMAIS AUTOPSIADOS E REFERENCIAS SOBRE SEUS PARASITOS

\section{MAMMALIA}

PRIMATES

CEBIDAE

Cebinae

Cebus azarae Rengg. ${ }^{1}$

Foram examinados três exemplares sob os números 6805, 6857 e 6858 , sendo um parasitado por cestodeo e todos por nematodeos pertencentes aos gêneros Oslerus, Physaloptera, Dipetalonema e ainda pela espécie Molineus torulosus (Molin, 1861).

\section{CHIROPTERA}

PHYLLOSTOMIDAE

Phyllostominae

Glossophaga soricina PALL.

Examinamos um só exemplar sob o número 6776, livre de parasitos.

\section{CARNIVORA}

\section{PROCYONIDÄE}

Procyoninae

Nasua narica L.

Foi examinado um exemplar sob o número 6852, parasitado por nematodeos filarideos, por acantocefalos e por formas larvares de cestodeos (Plerocercoides). Encontramos na pele deste coati dois carrapatos (Amblyomma fossum Neumann, 1899) ?

MUSTELIDAE

\section{Mustelinae}

\section{Tayra barbara (L.) ${ }^{3}$}

Foi examinado um exemplar sob o número 6885, parasitado por nematodeos filarideos e formas larvares de cestodeos (Plerocercoides). Na pele
(1) Carlos C. Vieira det.
(2) Henrique Aragão det.
(3) Carlos C. Vieira det. 
deste exemplar coletamos carrapatos (Amblyomma cayennense FABR. 1794) ${ }^{4}$ e um Trichodectes.

\section{RODENTIA}

MYOMORPHA

MURIDAE

\section{Sigmodontinae}

\section{Oryzomys sp.}

Foram examinados sete exemplares sob os números 6581, 6583, 6584, $6621,6756,6757$ e 6862, dos quais quatro não parasitados e três com nematodeos tricostrongilideos. Na pele do último exemplar encontramos acarianos.

\section{HYSTRICHOMORPHA}

\section{DASYPROCTIDAE}

\section{Dasyprocta azarae Licht. ${ }^{5}$}

Foi examinado um exemplar sob o número 6925, parasitado por nematodeos oxiurideos e tricurideos. Colhemos neste exemplar várias malofagas, dois sifonapteros e carrapatos (Amblyomma cayennense FABr. 1794) ${ }^{6}$.

\section{$C A V I I D A E$}

\section{Cavia sp.}

Examinamos três exemplares sob os números 6855, 6863 e 6895, sendo os dois primeiros parasitados por nematodeos pertencentes ao gênero Viannella.

\section{EDENTATA}

XENARTHRA

\section{$M Y R M E C O P H A G I D A E$}

\section{Tamandua tetradactyla (L.)}

Um exemplar foi examinado sob o número 6723, no qual não foram en contrados parasitos.

(4) Henrique Aragão det.

(5) Carlos C. Vieira det.

(6) Henrique Aragão det. 
AVES

TINAMIFORMES

TINAMIDAE

Crypturellus undulatus undulatus (Temm.)

Examinamos quatro exemplares sob os números 6571, 6727, 6789 e 6926, todos parasitados por cestodeos e por nematodeos pertencentes aos gêneros Ascaridia, Subulura e Cyrnea. No estomago de um dos exemplares cncontramos uma lagarta de lepidoptero.

Crypturellus parvirostris (Wagl.)

Examinamos dois exemplares sob os números 6721 e 6874, estando o segundo parasitado por nematodeos do gênero Subulura.

Crypturellus rataupa tataupa (Temm.)

Um só exemplar examinado sob o número 6802, parasitado por nematodeos tricostrongilideos e heteraquideos, estes pertencentes à tspécie Heterakis spiculatus (Cobbold, 1861).

Rhynchotus rufescens rufescens (Tемм.)

Foi examinado um exemplar sob o número 6661, não parasitado.

CICONIIFORMES

ARDEAE

ARDEIDAE

Ardeinae

Pilherodius pileatus (Bodd.)

Um exemplar examinado sob o número 6890, não parasitado.

Sirygma sibilatrix (Temm.)

Um exemplar examinado sob o número 6554, parasitado por trematodeos pertencentes a espécie Nephrostomum limai Travassos, 1922.

Tigrisoma lineatum marmoratum (VIEILL.)

Examinamos dois exemplares sob os números 6553 e 6619 , sendo o primeiro parasitado por cestodeos a o segundo por nematodeos ascarideos.

(7) Todas as aves foram determinadas por Carlos C. Vieira. 
CICONIAE

CICONIOIDEA

CICONIIDAE

Ciconiinae

Euxenura galeata (Molina)

Um exemplar examinado sob o número 6878 , parasitado por um trematodeo omfalometrineo e por duas espécies de nematodeos spirurideos.

Jabiru mycteria (Licht.)

Examinamos um exemplar sob o número 6850 , não parasitado.

THRESKIORNITHOIDEA

THRESKIORNITHIDAE

Threskiornithinae

\section{Harpiprion caerulescens (VIEILL.)}

Examinamos dois exemplares sob os números 6550 e 6808 , sendo o primeiro parasitado por cestodeos e trematodeos equinostomideos e ambos por trematodeos dicrocelideos.

Theristicus caudatus caudatus (BODD.)

Três exemplares foram examinados sob os números 6551, 6552 e 6728 , sendo o primeiro parasitado por nematodeos do gênero Tetrameres e o segundo por larvas de nematodeos enquistadas nas paredes do intestino. No estômago do primeiro exemplar encontramos dois batraquios, determinados por Antenor Leitão de Carvalho, do Museu Nacional, como Bufo granulosus Spix e Elachistocleis bicolor (VAlenc.). E' extremamente interessante o encontro de uma espécie de Bufo no estômago desta ave.

Mesembrinibis cayennensis (GM.)

Um único exemplar examinado sob o número 6932, livre de parasitos. Em seu estômago encontramos alguns moluscos (caramujos) muito pequenos.

\section{ANSERES}

ANATIDAE

Anatinae

Cairina moschata (L.)

Três exemplares examinados sob os números 6543, 6663 e 6664, sendo o segundo parasitado por nematodeos pertencentes ao gênero Súbulura. Pesquisa de hemo-parasitos positiva em todos os exemplares.

Nettion brasiliense (Gм.)

Um exemplar examinado sob o número 6587, parasitado por cestodeos. 
FALCONIFORMES

CATHARTAE

CATHARTIDAE

Coragips atratus foetens (Licht.)

Um exemplar examinado sob o número 6782, não parasitado.

Cathartes aura ruficollis Spix

Foram examinados três exemplares sob os nümeros 6626, 6627 e 6836 , sendo o primeiro parasitado por nematodeos ascarideos e por acantocefalos, e o último por acantocefalos, cestodeos e trematodeos holostomideos.

\section{FALCONES}

\section{FALCONIOIDEA}

\section{ACCIPITRIDAE}

\section{Buteoninae}

\section{Rupornis magnirostris superciliaris (VIEILL.)}

Sete exemplares examinados sob os números 6507, 6570, 6660, 6755, 6796, 6917 e 6931, dos quais um livre de parasitos, um parasitado por nematodeos do gênero Thelazia, cinco por acantocefalos do gênero Centrorkynchus e dois por cestodeos. No estômago de um dos exemplares encontramos restos de um rato e no de outro insetos (gafanhotos e cerambicideos) e repteis (lagartixas).

\section{FALCONIDAE}

Polyborinae

Milvago chimachima chimachima (VIEILl.)

Um exemplar examinado sob o número 6586, parasitado por nematodeos do gênero Thelazia.

\section{Polihieracinae}

\section{Gampsonix swainsonii VIGORS}

Um exemplar examinado sob o número 6923, livre de parasitos. Em seu estômago encontramos restos de repteis (lagartixas) e na sua pele pupiparas (Lynchia sp.).

\section{Falconinae}

Falco albigularis albigularis DAuD.

Examinamos dois exemplares sob os números 6695 e 6696, estando o segundo parasitado por nematodeos spirurideos. 
Cerchneis sparverius eidos (Peters)

Examinamos um exemplar sob o número 6610, parasitado por nematodeos pertencentes ao gênero Habronema.

\section{GALLIFORMES}

\section{GALLI}

\section{CRACOIDEA}

\section{CRACIDAE}

Ortalis canicollis pantanalensis CherRIE \& ReICH ${ }^{s}$

Examinamos sete exemplares sob os números $6559,6574,6576,6585$, 6611,6612 e 6613, sendo dois negativos, um parasitado por cestodeos e quatro por nematodeos do gênero Thelazia. Na pele do último exemplar colhemos pupiparas (Stilbometopa sp.). Pesquisa de hemoparasitos positiva em três exemplares.

\section{Pipile grayi (Pelz.)}

Seis exemplares foram examinados sob os números 6572, 6573, 6614, 6896, 6897 e 6898, sendo dois negativos, e quatro parasitados por nematodeos ascarideos, além de outros pertencentes aos gêneros Thelazia, Tetrameres e Pelecitus. Pesquisa de hemoparasitos positiva em três exemplares.

\section{GRUIFORMES}

\section{GRUES}

\section{GRUOIDEA}

\section{ARAMIDAE}

Aramus scolopaceus carao VIEILL.

Um exemplar examinado sob o número 6807, negativo.

\section{RALLOIDEA}

\section{RALLIDAE}

\section{Rallinae}

\section{Aramides cayanea cayanea (MuELl.)}

Foram examinados quatro exemplares sob os números 6825, 6906, 6907, e 6919, sendo três parasitados por nematodeos dos gêneros Tetrameres, Oxyspirura e Pelecitus. 


\section{CHARADRIIFORMES}

CHARADRII

JACANOIDEA

$J A C A N I D A E$

Jacana spinosa jacana (L.)

Dois exemplares examinados sob os números 6665 e 6666, negativos.

\section{CHARADRIOIDEA}

CHARADRIIDAE

Vanellinae

\section{Belonopterus chilensis lampronotus (WAGL.)}

Examinamos dois exemplares sob os números 6593 e 6867, ambos parasitados por cestodeos.

\section{COLUMBIFORMES}

\section{COLLIMBAE}

\section{COLUMBIDAE}

\section{Scardafella squammata squammata (LESSON)}

Examinamos 11 exemplares sob os números 6615, 6616, 6617, 6618, $6729,6740,6741,6742,6790,6816$ e 6912 , dos quais só dois parasitados por nematodeos, um por tricostrongilideos e outro por filarideos.

Columbina picui picui (Tемm.)

Examinamos um exemplar sob o número 6842, parasitado por nematodeos tricostrongilideos.

\section{Columbigallina talpacoti talpacoti (TemM.)}

Nove exemplares examinados sob os números 6628, 6629, 6630, 6632, $6646,6647,6648,6785$ e 6817 , dos quais o último parasitado por nematodeos tricostrongilideos.

\section{Leptoptila verreauxi ochroptera (PELZ.)}

Examinamos nove exemplares sob os números $6635,6719,6725,6726$, $6813,6840,6849,6880$ e 6913 , dos quais três parasitados por cestodeos e dois vor nematodeos tricostrongilideos. 


\section{CUCULIFORMES}

\section{CUCULI}

CUCULIDAE

\section{Piaya cayana cabanisi (AlleN)}

Examinamos oito exemplares sob os números $6662,6670,6720,6788$, 6793, 6826, 6854 e 6915, dos quais um negativo, dois parasitados por cestodeos e sete por nematodeos dos gêneros Histiocephalus, Cyrnea e Subulura. No estômago de um deles encontramos coleopteros crisomelideos (Doryphora sp.).

\section{Crotophaga ani (L.)}

Três exemplares examinados sob os números 6555, 6556 e 6557 , sendo dois parasitados por cestodeos, dois por acantocefalos do gênero Centrorhynchus e todos por nematodeos dos gêneros Histiocephalus e Subulura.

\section{Guira guira (GM.)}

Examinamos quatro exemplares sob os números $6680,6681,6682$, e 6683 , todos parasitados por nematodeos do gênero Subulura e por acantocefalos do gênero Centrorhynchus; um por cestodeos e dois por trematodeos pertencentes ao gênero Echinostoma e ainda pela espécie Eumegacetes medioximus Braun, 1901, (sin. - Eumegacetes perodiosus Travassos, 1922)"

9 - O reestudo do tipo de $E$. perodiosus Trav., 1922, ao lado do estudo do material agora colecionado e de outras amostras existentes na coleção helmintologica do Instituto Oswaldo Cruz faz-nos considerar idênticas as espécies de Travassos e Braun. Esta espécie descrita por Braun, em 1901, do intestino de Galbula grandis Lath. proveniente do Brasil e colecionadi por Natterer, é, em 1922, estudada por um de nós sob o nome de perodiosus, proveniente de cloaca de Piaya cayana (L.), oriundo de Mato Grosso. Tem ela agora sua distribuição alargada pela referência de um novo hospedador proveniente do mesmo Estado do Brasil, porem, de região s:tuada mais ao sul daquela referida em 1922 ( $\mathrm{S}$. João).

Na coleção do Instituto Oswaldo Cruz é ela representada por mais cinco amostras, de três outros hospedadores, que são:

a) Notharchus swainsoni (Gray \& Mitchell) (sin. - Bucco swainsoni Gray \&Mitchell) - uma amostra, proveniente de Angra dos Reis, Estado do Rio ;

b) Galbula rufoviridis Cab. - uma amostra, proveniente de Angra dos Reis, Estadis do Rio;

c) Crotophaga ani L. - três amostras, provenientes de Manguinhos, Rio de Janeiro.

Fica, pois, Eumegacetes medioximus BRAUN 1901, referido em seis hospedadores, e com a distribuição geográfica abrangendo o Rio de Janeiro (Manguinhos), a parte sul do Estado do Rio (Angra dos Reis) e o Estado de Mato Grosso (S. João, ao norte e Salobra, ao sul), senlo até agora a única espécie deste genero encontrada no Brasil.

Devemos salientar que Crotophaga ani L. como hospedador desta espécie foi referido por Lutz em 1928. Este mesmo autor encontrou-a na Venezuela (Maracay) parasitando a cloaca de Piaya cayana.

No relatório da excursão anterior referimos trematođeos pertencentes ao genero Eumegacetes em Jacana spinosa jacana (L.) O estudo deste material, agora feito, evidenciou pertencer ele ao genero Leucochloridium. 
PSITTACIFORMES

PSITT ACIDAE

Anodorhynchus hyacinthinus (LAth.)

Seis exemplares examinados sob os números 6547, 6548, 6549, 6676 , 6677 e 6809 , todos negativos.

Propyrrhura auricollis (CASSIN)

Examinamos doze exemplares sob os números 6532, 6533, 6591, 6592, $6690,6691,6692,6827,6828,6829,6830$ e 6889, todos negativos.

\section{Aratinga aurea aurea (GM.)}

Examinamos três exemplares sob os números 6577,6739 e 6745 , todos negativos.

\section{Nendayus nenday (VIEILL.)}

Cinco exemplares examinados sob os números 6831, 6832, 6833, 6834 e 6835, todos negativos.

\section{Pyrrhura borelli (Salv.)}

Examinamos seis exemplares sob os números 6537, 6538, 6539, 6568, 6569 e 6736. todos negativos.

\section{Tirica chiriri (VIEILl.)}

Dois exemplares examinados sob os números 6686 e 6818, ambos livres de parasitos.

\section{Amazona aestiva (L.)}

Três exemplares sob os números 6528, 6590 e 6693, não parasitados.

Pionus maximiliani siy (Sou ancé)

Examinamos três exemplares sob os números 6524,6588 e 6589 , sendo o primeiro parasitado por nematodeos do gênero Pelecitus.

\section{STRIGIFORMES}

STRIGIDAE

Otus choliba decussatus (Licht.)

Um exemplar sob o número 6843, não parasitado.

Glaucidium brasilianum (GM.)

Examinamos um exemplar sob o número 6856 , negativo. 
CAPRIMULGIFORMES

CAPRIMULGI

CAPRIMULGIDAE

Nyctidromus albicollis derbyanus (GouLD)

Examinamos um exemplar sob o número 6908, parasitado por cestodeos e por nematodeos spirurideos. Colhemos nesta espécie uma pupipara (Pseudolynchia sp.).

\section{MICROPODIIFORMES}

\section{TROCHILI}

\section{TROCHILIDAE}

\section{Eupetomena macroura macroura (GM.)}

Um exemplar examinado sob o número 6535, não parasitado.

Hylocharis chrysura (SHAw)

Examinamos quatro exemplares sob os números 6567, 6622, $6737 \mathrm{e}$ 6877 , todos negativos.

\section{TROGONIFORMES}

\section{TROGONIDAE}

\section{Trogonurus variegatus behni (GouLD)}

Doze exemplares examinados sob os números $6657,6658,6659,6708$, $6743,6801,6803,6823,6824,6839,6868$ e 6927 , dos quais dois não parasitados, os demais com nematodeos filarideos, spirurideos e outros pertencentes aos gêneros Tetrameres e Subulura. Nos músculos de um exemplar encontramos numerosos quistos de protozoarios.

\section{CORACIIFORMES}

\section{ALCEDINES}

\section{ALCEDINOIDEA}

ALCEDINIDAE

Megaceryle torquata torquata (L.)

Um exemplar examinado sob o número 6565 , não parasitado. 


\section{PICIFORMES}

GALBULAE

GALBULOIDEA

GALBULIDAE

Galbula rufoviridis (САВ.)

Examinamos três exemplares sob os números 6582,6651 e 6871 , todos negativos.

RAMPHASTOIDEA

RAMPHASTIDAE

Ramphastos toco Muell.

Foram examinados dois exemplares sob os números 6625 e 6669, ambos parasitados por cestodeos.

Pteroglossus castanotis australis CASSIN

Três exemplares examinados sob os números 6562, 6563 e 6564 , todos negativos.

PICI

PICIDAE

Leuconerpes candidus (OTто)

Examinamos dois exemplares sob os números 6844 e 6870, ambos negativos.

Piculus chrysochloros chrysochloros (VIEILL.)

Examinamos dois exemplares sob os números 6746 e 6930, ambos livres de parasitos.

Celeus lugubris (MaLH.)

Examinamos cinco exemplares sob os números 6522, 6752, 6841, 6869 e 6922, dos quais um negativo, três parasitados por cestodeos e quatro por nematodeos dos gêneros Cyrnea, Acuaria e Diplotriaena.

Scapaneus melanoleucus melanoleucus (GM.)

Dois exemplares sob os números 6606 e 6607, sendo o primeiro parasitado por nematodeos do gênero Pelecitus. Encontramos nos músculos deste exemplar numerosos quistos de protozoarios e no estômago do segundo duas larvas de cerambicideos. 
Veniliornis passerinus olivinus (MALH.)

Examinamos dois exemplares sob os números 6748 e 6929 , ambos negativos. No estômago do primeiro encontramos três larvas de cerambicideos.

Picumnus albosquamatus corumbanus LIMA

Examinamos três exemplares sob os números 6602, 6684 e 6804 , todos negativos. Encontramos no estômago do primeiro muitas formigas.

\section{PASSERIFORMES}

\section{TYRANNI}

\section{FURNARIOIDEA}

\section{DENDROCOLAPTIDAE}

Dendrocolaptes platyrostris intermedius BERL.

Dois exemplares examinados sob os números 6667 e 6668 , sendo o segundo parasitado por um cestodeo.

\section{Lepidocolaptes angustirostris bivittatus (Licht.)}

Examinamos quatro exemplares sob os números 6511, 6512, $6637 \mathrm{e}$ 6685 , sendo o segundo parasitado por nematodeos filarideos.

\section{Campylorhamphus trochilirostris lafresnayanus (D'ORB.)}

Examinamos três exemplares sob os números 6544,6744 e 6753 , sendo o primeiro parasitado por cestodeos e o último por um trematodeo do gênero Eutytrema.

Sittasomus griseicapillus griseicapillus (VIEILL.)

Três exemplares examinados sob os números 6517,6518 e 6655 , todos negativos.

\section{FURNARIIDAE}

Furnariinae

Furnarius rufus commersoni PELZ.

Foram examinados quatro exemplares sob os números 6502, 6503, 6542 , e 6566, sendo dois parasitados por nematodeos filarideos.

Fornarius leucops assimilis CAB. \& HeIne

Examinamos um exemplar sob o número 6887, não parasitado.

Synallaxis gujanensis albilora PELz.

Examinamos três exemplares sob os números 6795,6798 e 6872 , sendo o primeiro parasitado por nematodeos do gênero Tetrameres. 


\section{Phacellodomus rufifrons sincipitalis САВ.}

Três exemplares examinados sob os números 6643, 6712 e 6713, sendo o primeiro parasitado por trematodeos do gênero Eurytrema.

FORMICARIIDAE

Formicariinae

Taraba major (VIEILL.)

Examinamos dois exemplares sob os números 6700 e 6724 , ambos parasitados por nematodeos do gênero Tetrameres.

Formicivora rufa rufatra (LAFr. \& D'Orb.)

Um exemplar examinado sob o número 6645. não parasitado.

Cercomacra melanaria (MÉNÉTr.)

Examinamos dois exemplares sob os números 6653 e 6873, ambos negativos.

\section{TYRANNIDAE}

Taeniopterinae

Xolmis velata (LICHT.)

Três exemplares examinados sob os números 6640, 6641 e 6847 , todos negativos. No estômago do último encontramos, ao lado de detritos vegetais, um gafanhoto.

Xolmis irupero (VIEILl.)

Um exemplar examinado sob o número 6797, não parasitado.

Copurus colonus (VIEILL.)

Foi examinado um exemplar sob o número 6749 , negativo.

Platyrhynchinae

Tolmomyias sulphurescens (SpIX)

Três exemplares examinados sob os números 6541, 6597 e 6598, sendo o primeiro parasitado por nematodeos spirurideos.

Todirostrum latirostris (PElz.)

Foi examinado um exemplar sob o número 6601, não parasitado.

Euscarthmornis margaritaceiventer (LAFR. E D'ORB.)

Um exemplar examinado sob o número 6521, não parasitado. 
Serpophaga inornata SALV.

Examinamos um exemplar sob o número 6604, negativo.

Elaiinae

Leptopogon amaurocephalus $\mathrm{CAB}$.

Foi examinado um exemplar sob o número 6671, negativo.

Camptostoma obsoletum (Tемм.)

Um exemplar examinado sob o número 6760 , negativo.

Elaenia gaimardi D'ORB.

Dois exemplares examinados sob os números 6716 e 6717, ambos ne. gativos.

Suiriri affinis (BURM.)

Examinamos dois exemplares sob os números 6654 e 6704, ambos não parasitados.

Pitangus sulphuratus maximiliani (САВ. \& HEINE)

Dois exemplares examinados sob os números 6732 e 6848, ambos negativos.

Tyranninae

Pyrocephalus rubinus (Bodd.)

Examinamos dois exemplares sob os números 6706 e 6758, ambos negativos.

Myiarchus tyrannulus bahiae BERL.

Examinamos cinco exemplares sob os números 6508, 6509, 6599, 6600 e 6888 , sendo o último parasitado por nematodeos filarideos.

COTINGIDAE

\section{Attilinae}

Casiornis rufa (VIEILL.)

Quatro exemplares examinados sob os números 6652, 6694, 6703 e 6751 , todos negativos.

TURDIDAE

Turdus leucomelas (VIEILL.)

Um exemplar examinado sob o número 6715 , parasitado por trematodeos do gênero Lyperosomum 


\section{Turdus rufiventris (VIEILL.)}

Examinamos três exemplares sob os números 6794,6811 e 6851 , sendo o primeiro negativo, o segundo parasitado por cestodeos e o terceiro por trematodeos dicrocelideos.

\section{TROGLODYTIDAE}

\section{Heleodytes unicolor LAFR.}

Três exemplares examinados sob os números 6701,6702 e 6845 , todos negativos.

SYLVIIDAE

\section{Polioptila dumicola (VIEILL.)}

Examinamos dois exemplares sob os números 6520 e 6709, ambos negativos.

\section{MNIOTILTIDAE}

Compsothlypis pitiayumi (VIEILL.)

Foi examinado um exemplar sob o número 6718 , não parasitado.

Basileuterus hypoleucus BonAP.

Examinamos dois exemplares sob os números 6603 e 6705 , sendo o último parasitado por nematodeos filarideos.

Ateleodacnis speciosa (WIED)

Foi examinado um exemplar sob o número 6605, negativo.

THRAUPIDAE

\section{Thraupis sayaca (L.)}

Examinamos nove exemplares sob os números $6510,6540,6853,6860$, $68616881,6909,6910$ e 6911 , dos quais somente o terceiro parasitado por um nematodeo do gênero Aprocta. Pesquisa de hemoparasitos positiva em um exemplar.

Rhamphocelus carbo centralis Hellm.

Três exemplares examinados sob os números 6595,6596 e 6806 , todos negativos.

Eucometis penicillata albicollis (LAFr. \& D'ORB.)

Examinamos quatro exemplares sob os números 6697, 6698, 6894, e 6914, todos livres de parasitos. 
FRINGILLIDAE

Oryzoborus angolensis (L.)

Um exemplar examinado sob o número 6519 , não parasitado.

Saltator caerulescens (VIEILL.)

Sete exemplares examinados sob os números $6515,6516,6687,6846$. 6879, 6916 e 6924, todos negativos.

Volatinia jacarina (L.)

Foi examinado um exemplar sob o número 6650 , não parasitado.

Spinus ictericus alleni RIDGW.

Examinamos dois exemplares sob os números 6505 e 6506, ambos negativos.

\section{Arremon flavirostris devillei Des Murs}

Examinamos três exemplares sob os números 6623,6624 e 6699 , todos negativos.

\section{Coryphospingus cucullatus (MuELL.)}

Examinamos oito exemplares sob os números $6514,6636,6707,6735$. 6787, 6799, 6815 e 6882, todos negativos.

Paroaria capitata (LAFr. \& D'ORB.)

Um exemplar examinado sob o número 6594, parasitado por nematodeos do gênero Tetrameres.

\section{ICTERIDAE}

\section{Cassicinae}

\section{Ostinops decumanus maculosus CHAPM.}

Examinamos dois exemplares sob os números 6501 e 6644 , sendo o primeiro parasitado por nematodeos e cestodeos e o segundo por trematodeos dicrocelideos.

\section{Cacicus chrysopterus (VIGORS)}

Examinamos três exemplares sob os números 6620,6711 e 6837 , todos negativos.

\section{Archiplanus solitarius (VIEILl.)}

Examinamos três exemplares sob os números 6649,6810 e 6921 , sendo o primeiro parasitado por nematodeos do gênero Pelecitus e o segundo por nematodeos do gênero Oxyspiruta. 
Sturnellinae

Icterus pyrrhopterus (VIEILL.)

Examinamos quatro exemplares sob os números 6642, 6710,6750 e 6859 , sendo o primeiro parasitado por um trematodeo dicrocelideo.

\section{Quiscalinae}

Gnorimopsar chopi (VIEILl.)

Examinamos oito exemplares sob os números 6633, 6638.6639, 6673. $6674,6675,6678$ e 6679, sendo dois negativos, um parasitado por nematodeos filarideos e outro por cestodeos.

\section{CORVIDAE}

\section{Cyanocorax chrysops (VIEILL.) ${ }^{10}$}

Examinamos nove exemplares sob os números $6560,6738,6819,6820$, 6821, 6899, 6900, 6905 e 6928, sendo dois negativos, sete parasitados por nematodeos spirurideos e filarideos, um por cestodeos e outro por trematodeos do gênero Prosthogonimus. Em um deles encontramos na pele vários nodulos com trombideos.

\section{Cyanocorax cyanomelas (VIEILL.)}

Examinamos vinte exemplares sob os números 6526, 6534, 6608, 6609, 6634, 6688, 6689, 6730, 6731, 6733, 6734, 6759, 6786, 6812, 6822, 6864, $6865,6866,6886$ e 6918 , dos quais seis negativos, um parasitado por cestodeos, três por trematodeos dicrocelideos e quatorze por nematodeos filarideos e spirurideos.

\section{REPTILIA}

\section{OPHIDIA}

\section{CROT ALIDAE}

\section{Bothrops sp.}

Um exemplar examinado sob o número 6504, com larvas de nematodeos enquistadas na parede externa do estômago. Na cavidade deste orgão encontramos uma lagartixa. 


\section{EMYDOSAURIA}

\section{CROCODILIDAE}

\section{Caiman sclerops (GRAY)}

Dois exemplares examinados sob os números 6580 e 6672, ambos parasitados por linguatulideos do gênero Sebekia.

\section{LACERTILIA}

\section{IGUANIDAE}

\section{Tropidurus spinulosus (COPE)}

Examinamos vinte e três exemplares sob os números $6523,6525,6527$, $6529,6531,6536,6545,6546,6579,6631,6656,6714,6722,6747,6783$. $6784,6791,6792,6800,6884,6891,6892$ e 6893, dos quais doze negativos, e onze parasitados por nematodeos spirurideos ${ }^{11} \mathrm{e}$ outros pertencentes aos gêneros Physalcptera e Thelandros.

\section{SCINCIDAE}

\section{? Mabuia dorsivittata COPE}

Examinamos dois exemplares sob os números 6513 e 6883, ambos parasitados por nematodeos do gênero Thelandros.

\section{AMPHIBIA 12 \\ $B U F O N I D A E$}

\section{Bufo granulosus SPIX}

Seis exemplares examinados sob os números 6777, 6778, 6779, 6780, 6781 e 6814, dos quais dois parasitados por nematodeos.

\section{HYLIDAE}

\section{Hyla phrynoderma (BouL.)}

Um exemplar examinado sob o número 6920 , negativo.

11 - No relatório da excursão anterior assinalamos nematodeos do genero Typhlonema nesta espécie. O estudo agora feito, por um de nós, daquele material, ao lado de novas amostras obtidas, evidencia serem nematodeos spirurideos, e não pertencentes ao genero anteriormente referido.

12 - Determinados por A. Leitã̃o de Carvalho. 
PISCES ${ }^{13}$

SELACHII

HYPOTREMATA

$D A S Y A T I D A E$

Ellipesurus motoro (Mull. \& TROSCH.)

Foi examinado um exemplar sob o número 6904, parasitado por cestodeos.

NEOPTERYGII

CHARACIDAE

Tetragonopterinae

Tetragonopterus argenteus Cuv:

Examinamos três exemplares sob os números 6558, 6561 e 6903, todos parasitados por trematodeos e o primeiro tambem por nematodeos do gênero Contracaecum.

Astyanax fasciatus (Cuv.)

Um exemplar examinado sob o número 6575 , não parasitado.

Leporininae

Leporinus reinhardti LTK.

Examinamos um exemplar sob o número 6902, negativo.

Serrasalmoninae

Pygocentrus nattereri (KNER) ${ }^{14}$

Examinamos dezenove exemplares sob os números $6530,6578,6754$, $6761,6762,6763,6764,6765,6766,6767,6768,6769,6770,6771,6772,6773$, 6774,6775 e 6875 , dos quais sete negativos, dois parasitados por linguatulideos e doze por nematodeos dos gêneros Contracaecum e Procamallanus.

\section{SILUROIDEA}

\section{SILURIDAE}

\section{Pimelodinae}

Pimelodus clarias (L.)

Três exemplares examinados sob os números 6838, 6876 e 6901, dos quais o segundo negativo e os demais parasitados por cestodeos, tendo o primeiro ainda nematodeos do gênero Procamallanus.

13 - Determinados por P. DE Miranda Ribeiro.

14 - No relatório da excursão anterior o que referimos como $P$. piraya deve se relacionar a esta espécie. 


\section{OBSERVAÇÕES MÉDICAS}

As observações médicas foram realizadas na pequena população de Salobra, local de nossa permanência durante dez dias. Logo ao chegarmos, na tarde do dia 20, verificamos ter se transformado esta vila em intenso fóco de impaludismo, em flagrante contraste com seu aspecto sadio, observado em Outubro do ano passado. Este surto paludico muito intenso já acarretára a retirada de alguns moradores, enquanto outros se aprestavam para abandonar a região, que se tornára tão inhospita. Iniciamos logo a obtenção de informes sôbre os moradores ainda aí existentes. sua alimentação e modo de

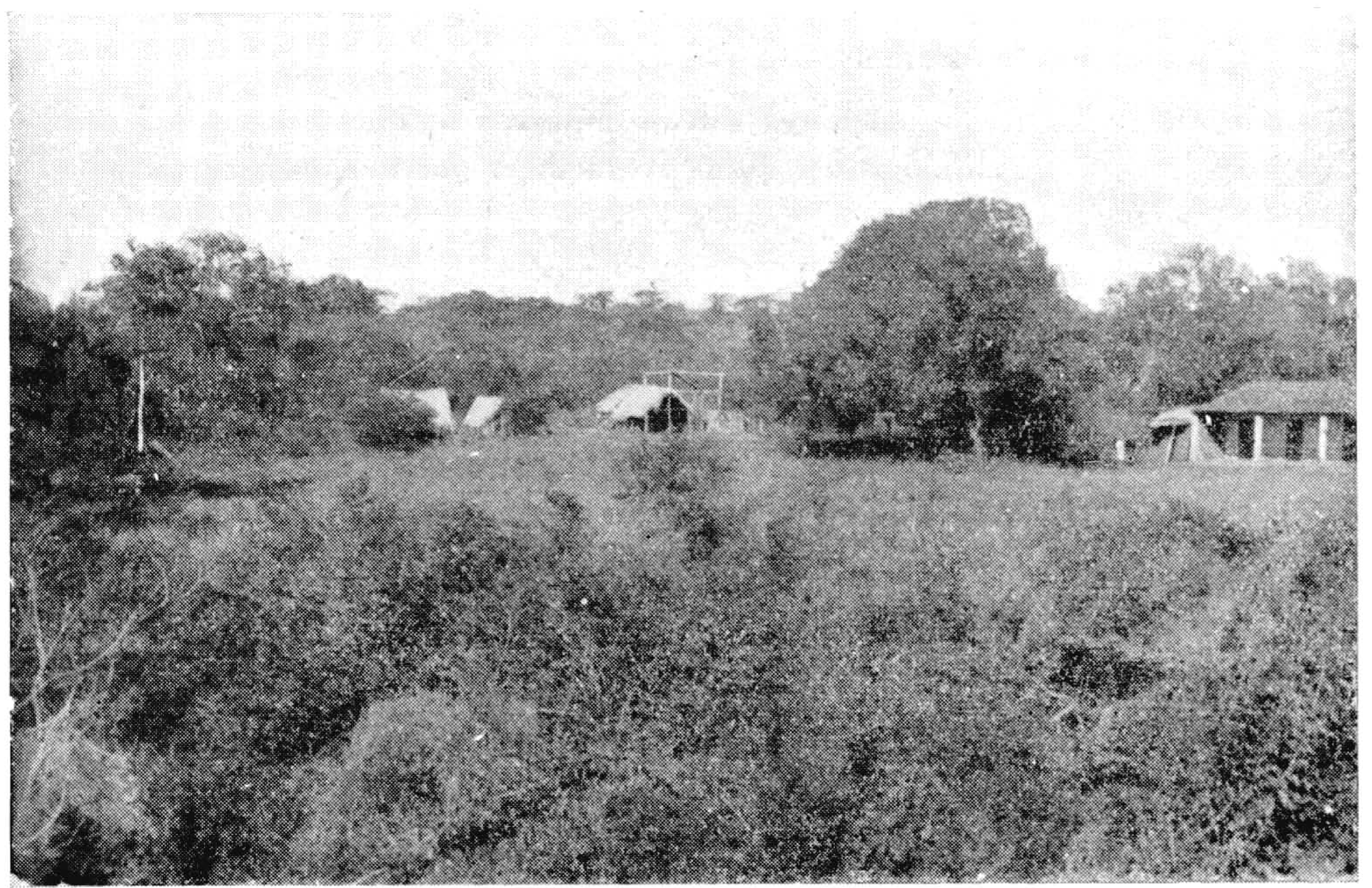

Fig. 3 - Aspecto de Salobra. Habitacoes.

vida, sintomas subjetivos etc. Nessa mesma tarde grande quantidade de mosquitos foi coletada, sendo enorme a porcentagem de anofelinos capturados $\mathrm{Na}$ manhã seguinte iniciamos os exames de doentes, que eram sempre medicados. Na tarde deste dia começamos a quininisação de todos os membros da comissão. As pesquisas para obtenção de flebotomos deram sempre resultados negativos, durante os vários dias em que aí permanecemos. A captura de barbeiros ou "chupões" foi positiva para o Eutriatoma sordida, em galinheiro. Estes hemipteros, trazidos vivos para o Instituto Osvaldo Cruz, fo- 
ram aí examinados por HERMAN LENT, tendo se mostrado negativos para a infecção por $S$. cruzi. Os mosquitos que nos martirisaram todas as tardes foram sempre colecionados. A observação de seus habitos e a pesquisa de larvas em coleções dágua existentes à margem esquerda do rio Miranda, indicam como fóco de criação a margem oposta do rio, donde, à tarde, vem ver dadeiro aluvião destes insetos cair sobre as poucas casas de Salobra. Numerosas dissecções, para evidenciar a infecção de mosquitos por plasmodios, foram feitas por J. LANE, dando como resultado uma fraca porcentagem de infecção.

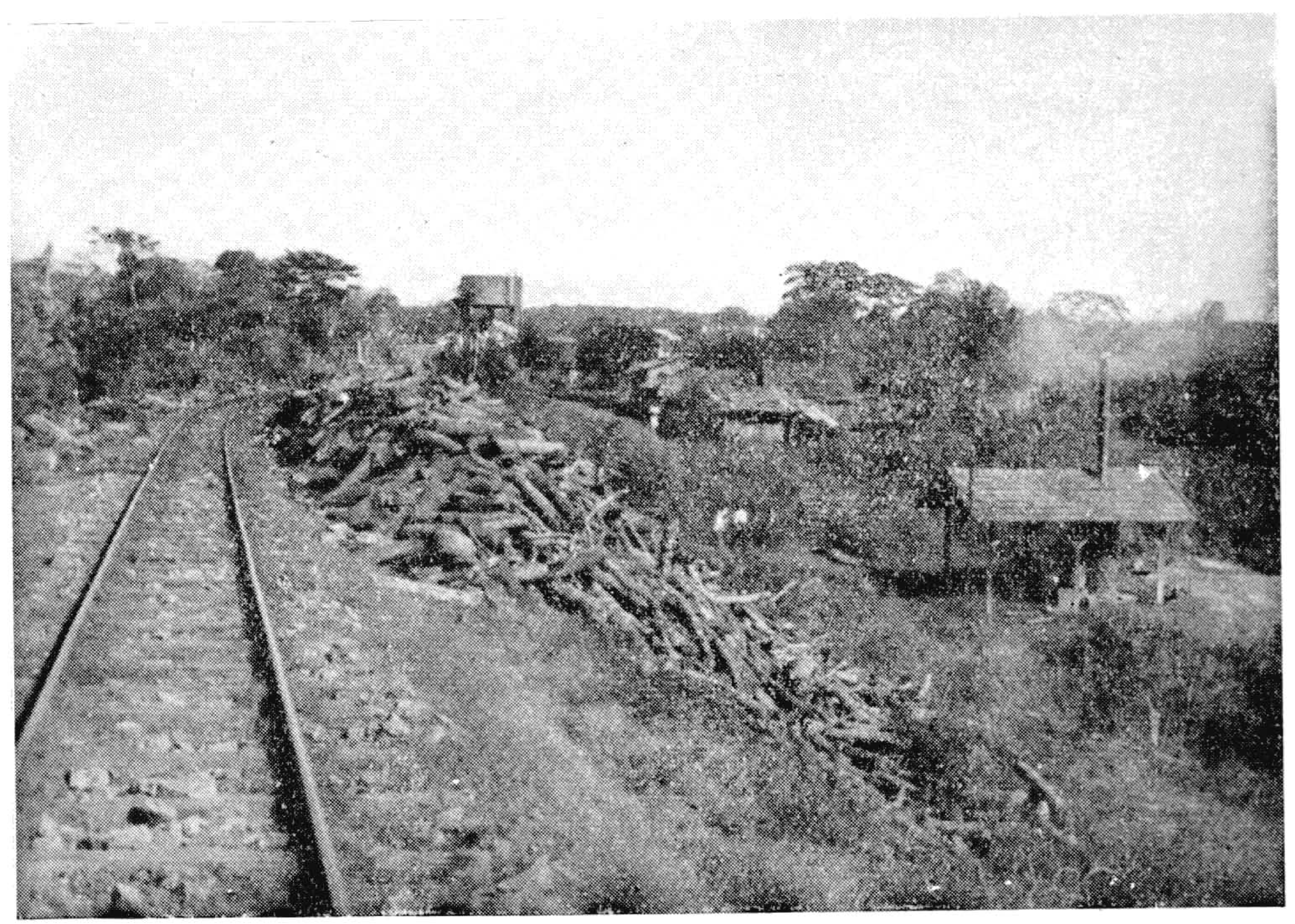

Fig. 1 - Aspecto de salobra. Habitaçöes e linha férred.

O surto palúdico agora observado em Salobra é bastante curioso, por parecer a época pouco propícia ao seu desenvolvimento, principalmente devido à temperatura bastante baixa que encontramos, dando-nos dias frios $\left(12^{\circ} \mathrm{C}\right.$.) e noites extremamente difíceis de suportar sem o abrigo proporcionado pelo carro dormitório. A grande quantidade de mosquitos deve ser resultante da pequena enchente do pantanal do Miranda, havida recentemente, porem já em seu fim. Não fôra este fato e provavelmente Salobra continuaria a ser salubre. 
O abaixamento da temperatura se reflete na alimentação dos habitantes, que teem o peixe ausente de seus cardapios. Explicam êles este fato pela fuga dos peixes para as porções mais fundas do rio, onde a água é menos fria. Aliás, pudemos perfeitamente observar a enorme dificuldade de capturar qualquer peixe, mesmo piranhas, que são, no entanto, extremamente voráses .

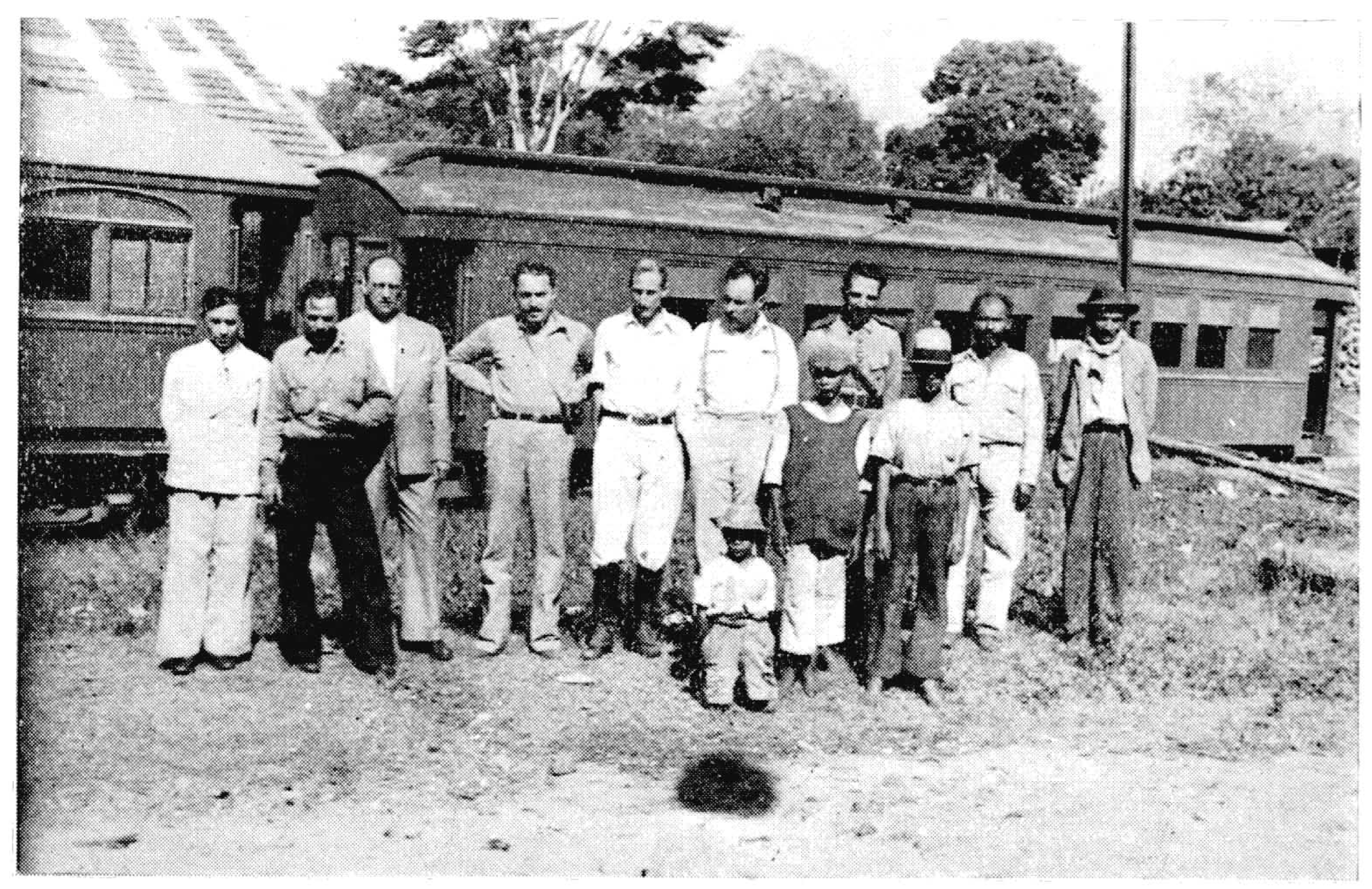

Fig. 5 - Membros da Comissão, em Salobra.

Ao instalarmos nossos laboratórios e cosinha em pequena habitação da Estrada, imediatamente se agregou à "boia" cerca de um quinto dos moradores, que tiveram, assim, a alimentação melhorada e aumentada. Ao nos retirarmos deixamos Salobra sem impaludado febril, com sua população mais esperançada e ativa.

Nossas observações evidenciaram : a) - existência de 50 moradores, dos quais 49 com impaludismo, estando alguns já em tratamento pela Plasmoquina, comprada em Miranda; b) - um caso de bronquite, com fortes acessos de tosse; c) - 3 casos de conjuntivite banal; d) - um caso de helmintose (ascariose); e) - presença de P. vivax, agente da terçã benigna, no sangue de todos os doentes febrís. 
Como vemos, o grande flagelo é representado pela malária, com uma incidência de praticamente $100 \%$, inteiramente contrária às observações feitas anteriormente, quando da nossa viagem à esta região, em Outubro de 1938.

Não nos foi possivel examinar cães e gatos, porquanto era absoluta a ausência destes animais no local. Os poucos cães existentes em Outubro passado haviam morrido, segundo informações que nos foram dadas.

\section{OBSERVAÇÕES ZOOLÓGICAS}

As pesquisas zoológicas foram bastante proveitosas em vários grupos e extremamente pobres em outros. Assim, entre os vertebrados salientam-se as aves, que concorreram em porcentagem elevadíssima, fornecendo ao Departamento de Zoologia uma coleção numerosa e interessante, e aos técnicos do Instituto Osvaldo Cruz a realisação de exames parasitológicos, para a coleta de helmintos e pesquisas de hemoparasitos, principalmente. Os mamiferos, como sempre representados por um número relativamente pequeno, forneceram no entanto, alguns exemplares valiosos, com material helmintico interessantíssimo. Os repteis, tambem em quantidade pequena, foram representados principalmente por uma espécie de calango, praticamente a única existente em maior abundância, e que era possivel capturar durante o dia, nas horas de sol mais intenso. A grande surpresa, entretanto, foi a verificação da inexistência de batraquios, que, embora procurados com insistència, não foram sinão representados por poucos exemplares. Aliás, estes foram coletados de dia, em pequena coleção dágua encontrada ao lado do prédio da Estação. A procura de batráquios à noite, com o auxílio de lanterna, foi sempre infrutifera. Os peixes, tambem pouco abundantes, forneceram, ainda assim, alguns parasitos de valor.

$\mathrm{Na}$ fauna de invertebrados não parasitos observava-se uma pobreza muito grande. Assim, miriapodos e aranhas, abundantes em Outubro de 1938, eram agora dificeis de encontrar, principalmente os primeiros. Os insetos, excetuando mosquitos, tambem estavam escassos, principalmente alguns grupos, como os cerambicideos, dos quais somente dois exemplares foram obtidos.

A pesquisa de ninhos de ave (Phacellodomus rufifrons sincipitalis CaB.) revelou a presença de: coleopteros (várias espécies, entre as quais, muito abundante, uma de um lindo cassidideo), poucos blatideos e himenopteros, hemipteros (duas espécies, sendo uma o $P$. coreodes Bergroth), larvas de coleopteros, poucos araneideos e numerosos pseudo escorpiões. Não foram encontrados miriapodos nos ninhos examinados, os quais eram extremamente comuns na excursão anterior. A maior intensidade no serviço de autopsias tornou menor o tempo disponivel para estas pesquisas, razão pela qual somente cinco ninhos foram examinados. 
Entre os culicideos e simulideos coletados foram já determinados por J. Lane as seguintes espécies: Anopheles (Nyssorhynchus) triannulatus (Neiva \& Pinto, 1922); Anopheles (Nyssorhynchus) darlingi Root, 1926; Anopheles (Nyssorhynchus) albitarsis ArribalzÁgA, 1878; Psorophora (Janthinosoma) ciliata FABR.; Aedes (Ochlerotatus) fulvus (WIED., 1828); Aedes (Ochlerotatus) scapularis Rond.; Aedes (Ochlerotatus) nubilus Тнеов.; Aedes (Ochlerotatus) serratus Тнеов. e Simulium amazonicum LuTz.

Entre os ropalomerideos, muscideos, califorideos e sarcofagideos coletados foram já determinados por H. DE SouSA LOPES as seguintes espécies: Willistoniella pleuropunctata WIED.; Morellia bipuncta (WIED.); Orthellia pruna Shann. E Del PonTe; Lucilia cuprina WIED.; Oxysarcodexia aurifinnis (WALK.) e Chaetoravinia trivittata (Tows.). 